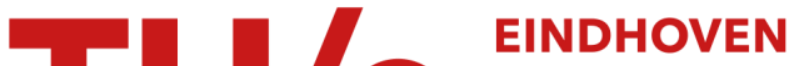 \\ UNIVERSITY OF \\ TECHNOLOGY
}

\section{Impact of design variables on balancing markets}

\section{Citation for published version (APA):}

Frunt, J., Kling, W. L., Hermans, R. M., Nobel, F., \& Boer, de, W. W. (2010). Impact of design variables on balancing markets. In Proceedings of the 7th IEEE International Conference on the European Energy Market (EEM'10), 23-25 June 2010, Madrid, Spain (pp. 1-6). Institute of Electrical and Electronics Engineers. https://doi.org/10.1109/EEM.2010.5558680

DOI:

10.1109/EEM.2010.5558680

Document status and date:

Published: 01/01/2010

\section{Document Version:}

Publisher's PDF, also known as Version of Record (includes final page, issue and volume numbers)

\section{Please check the document version of this publication:}

- A submitted manuscript is the version of the article upon submission and before peer-review. There can be important differences between the submitted version and the official published version of record. People interested in the research are advised to contact the author for the final version of the publication, or visit the $\mathrm{DOI}$ to the publisher's website.

- The final author version and the galley proof are versions of the publication after peer review.

- The final published version features the final layout of the paper including the volume, issue and page numbers.

Link to publication

\section{General rights}

Copyright and moral rights for the publications made accessible in the public portal are retained by the authors and/or other copyright owners and it is a condition of accessing publications that users recognise and abide by the legal requirements associated with these rights.

- Users may download and print one copy of any publication from the public portal for the purpose of private study or research.

- You may not further distribute the material or use it for any profit-making activity or commercial gain

- You may freely distribute the URL identifying the publication in the public portal.

If the publication is distributed under the terms of Article 25fa of the Dutch Copyright Act, indicated by the "Taverne" license above, please follow below link for the End User Agreement:

www.tue.nl/taverne

Take down policy

If you believe that this document breaches copyright please contact us at:

openaccess@tue.nl

providing details and we will investigate your claim. 


\title{
Impact of design variables on balancing markets
}

\author{
J. Frunt, Student Member, IEEE, W. L. Kling, Member, IEEE, \\ R. M. Hermans, Student Member, IEEE, F. A. Nobel, W. W. de Boer
}

\begin{abstract}
In electrical power systems there must always exist a balance between generation and load. Any imbalance will result in a frequency deviation and a deviation from the scheduled cross border exchange. To maintain and restore the balance in a certain area balancing systems exist. Balancing systems based on balance responsibility are affected by several design variables. This article discusses the effect of the programme time unit length and the gate-closure time.
\end{abstract}

Index Terms-Ancillary services, Balancing, Balance responsibility, Programme time unit, Gate-closure time.

\section{INTRODUCTION}

n electrical power systems there must always be a balance between the generation and load of electricity. Any imbalance will instantaneously be compensated by a change in the frequency and mostly results in a deviation from the scheduled cross-border exchange [1]. To settle imbalance a system of balance responsibility is in use in many market areas [2], [3].

Balance responsibility is defined in [3] as the responsibility for keeping the net balance on all the connections within its control and facing the liability consequences if this is not achieved. The liability in case of imbalance involves the payment of an imbalance charge to the operator of the market area. The imbalance charge consists of an imbalance price for every MWh of imbalance that has occurred during a predefined settlement period.

Therefore, all balance responsible parties (BRPs) need to inform the transmission system operator (TSO) in their market area about their expected net trade with other BRPs. This net exchange must be stated in terms of energy per programme time unit (PTU), in a schedule which has to be sent to the TSO before the gate-closure time (GCT). The GCT is defined in [3] as the point at which generation and load parties must notify the TSO of their expected physical positions at real time. At this point in most European markets, the possibilities for bilateral trading (with counter parties other than the TSO) therefore cease.

This work is financially supported by the Dutch Ministry of Economic Affairs.

J. Frunt, W. L. Kling and R. M. Hermans are in Eindhoven University of Technology, Eindhoven, 5600MB, the Netherlands (e-mail: j.frunt@tue.nl, w.l.kling@tue.nl, r.m.hermans@tue.nl).

F. A. Nobel is in TenneT TSO b.v., Arnhem, the Netherlands (e-mail: f.nobel@tennet.org).

W. W. de Boer is in KEMA NV, Arnhem, the Netherlands (e-mail: wouter.deboer@kema.com).
Usually the GCT is scheduled on the day before to allow the TSO to perform consistency checks and to secure the grid. At the actual moment of delivery, all BRPs are supposed to behave exactly as stated beforehand in their schedule. If the traded energy at the end of the agreed PTU deviates from the beforehand stated value, the difference will be settled between the BRPs and the TSO. Depending on both the balancing situation in the control area and their individual balance, the BRPs either receive or pay the imbalance price to the TSO.

The introduction of renewable electricity generation, which has less predictability and larger variations in time [4] with respect to conventional large-scale generation, as well as the further adaptation of market players to the liberalised electricity market, leads to changes in the balancing strategies of BRPs [5]. The further integration of markets leads to increasing cross-border flows and increasing variations of these at fixed times. This results in consistent frequency disturbances which tend to become ever more severe and intolerable over time [6].

Different design variables for imbalance systems determine the operation of balancing markets. By changing these design variables, responsibility and effort can be shifted from the BRPs to the TSO and vice versa. This paper will discuss two different design variables of the imbalance system. These variables are (1) the length of the programme time unit and (2) the gate-closure time. Section 2 of this paper will discuss the imbalance system and different types of imbalances. Section 3 will elaborate on the effect of changing the programme time unit length. Section 4 will elucidate on the gate-closure time. Conclusions of the research will be given in section 5 .

\section{IMBALANCE SETTLEMENT}

To balance generation and load of electricity at all times balancing systems are in use. This section will discuss a balancing system based on balance responsibility.

\section{A. Balance responsibility}

Within the European power system, the transmission system operators are responsible to maintain the balance in the grid [7]. Although implementations vary across different countries [2], [7], most implementations are based on balance responsibility [8], [9]. Balance responsibility means that any party (i) connected to the power system has the obligation to submit a schedule of its expected energy exchange $\left(E_{k}{ }^{i}\right)$ with the grid for each period of time $(\mathrm{k})$, or PTU, in the next day to its TSO. The TSOs verify the consistency of these schedules using (1) for all PTUs (k) in the next day and subsequently approve them. During the operational day, all connections 
have to behave according to their beforehand stated schedule. However, connections are free to choose their power exchange profile $\left(\mathrm{P}_{\mathrm{k}}{ }^{\mathrm{i}}(\mathrm{t})\right)$ within the PTU but any deviation in the energy exchange from the beforehand stated schedule will be regarded as imbalance $\left(\mathrm{I}_{\mathrm{k}}{ }^{\mathrm{i}}\right)$ for that specific period of time $(\mathrm{k})$ as in (2).

$$
\begin{aligned}
& \sum_{i} E_{k}^{i}=0 \\
& \int_{p t u_{k}} P_{k}^{i}(t) d t-E_{k}^{i}=I_{k}^{i}, \quad t \in P T U_{k}
\end{aligned}
$$

As it is impractical for all individual connections to send in a schedule of the expected energy exchange, individual connections can be aggregated into balance responsible parties [10], [11], [12]. A balance responsible party then takes over the responsibility for the creation and behaving according to schedules but it can make use of aggregation effects. This aggregation generally leads to improved quality of predictions of energy exchanges.

\section{B. Three types of imbalance}

On a control area level, imbalance is defined as a function of both frequency deviation and the deviation from the expected cross-border exchange [7]. This area control error (ACE) is a measure for the actual imbalance within the control area as it counts the effect of primary control actions for disturbances in other control areas. The area control error is given in (3).

$$
A C E_{j}(t)=\Delta P_{j}(t)+k_{j} \Delta f(t)
$$

Here $\mathrm{ACE}_{\mathrm{j}}(\mathrm{t})$ is the area control error in control area $\mathrm{j}$, $\Delta \mathrm{P}_{\mathrm{j}}(\mathrm{t})$ is the difference between expected cross-border power exchange and the real power exchange, $\mathrm{k}_{\mathrm{j}}$ is the contribution of control area $\mathrm{j}$ to primary control per $\mathrm{Hz}$ and $\Delta \mathrm{f}(\mathrm{t})$ is the frequency deviation at time $t$. Normally the ACE is calculated by the TSO every 1 to 4 seconds to determine the deviation between generation and load within the control area.

To minimise the ACE the TSOs procure ancillary services (AS) for balancing from one or more BRPs which are selected via a bidding ladder. BRPs that have reserve capacity available are either requested or obliged to bid this capacity in the imbalance system. Bidding ladders exist for both positive energy (selling) and negative reserve energy (buying). As prices for reserve power are generally higher than prices for energy on the spot market, it is profitable for BRPs to reserve part of their capacity as reserve power [8], [9], [13]. During each PTU (k), all BRPs (i) whose imbalances $\left(\mathrm{I}_{k}{ }^{\mathrm{i}}\right)$ have an aggravating effect on the ACE will pay the imbalance price while all BRPs (i) whose imbalances $\left(\mathrm{I}_{k}{ }^{i}\right)$ have a mitigating effect on the ACE will receive the imbalance price. It can be concluded that BRPs are only rewarded or penalised for their energy deviation with respect to the schedule per PTU.

Next to the imbalances $\mathrm{ACE}_{\mathrm{j}}(\mathrm{t})$ and $\mathrm{I}_{\mathrm{k}}{ }^{\mathrm{i}}$, a third type of imbalance exists. The TSO is responsible for a relatively smooth transition of cross-border transactions in subsequent time frames. Therefore it is decided that the TSO should implement a slope in the power profile from 5 minutes before the agreed time of change until 5 minutes after the agreed time of change [7]. The three types of imbalance are illustrated in Fig. 1.

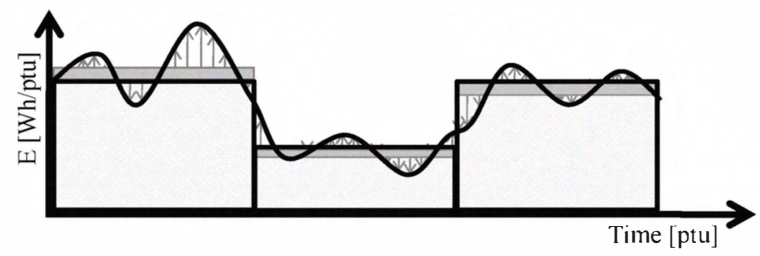

(a)

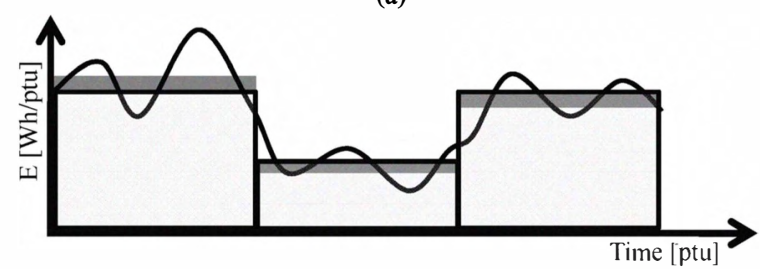

(b)

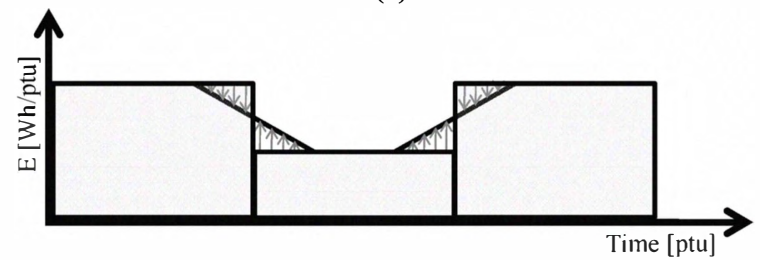

(c)

Fig. 1. Three types of imbalances exist. (a) Imbalance within the PTU is dealt with by the TSO. (b) Imbalance over the PTU is dealt with by the BRPs. (c) Imbalance between two PTUs is dealt with by the TSO.

\section{PRogramme Time UNiT}

As energy is a merchantable product while power is not, electricity trades are always in terms of energy per fixed time interval or a multiple of this. This unit of time is also called the programme time unit (PTU). Within a PTU, both parties involved in a trade are allowed to change their power profile as long as the total energy traded at the end of the PTU is in accordance with the agreed amount of energy. The actual system balance however, is the momentary balance between generation and load and is decoupled from the PTU. As marginal costs of power plants are usually quadratic functions of the power output [12], while other costs are usually negligible, the economically optimal schedule for a power plant during a PTU is a rectangular block with constant power during the full trading period. Load however is more continuous. As discrepancies between load and generation result in imbalance, the optimisation of schedules based on marginal costs leads to increasing frequency deviations [6]. Different market areas in Europe use different PTU lengths as indicated in Table I [13]. Due to these differences in PTU lengths, most cross-border trades in the European grid are done per hour.

TABLE I

SETTLEMENT PERIOD FOR BALANCING IN SEVERAL EUROPEAN MARKET

\begin{tabular}{|c|c|}
\multicolumn{2}{|c|}{ CounEAS [13] } \\
\hline $\begin{array}{c}\text { Netherlands, Italy, Austria, } \\
\text { Germany, Belgium, Luxembourg }\end{array}$ & Settlement Period [minutes] \\
\hline England \& Wales, France & 30 \\
\hline $\begin{array}{c}\text { Poland, Sweden, Norway, Denmark, } \\
\text { Slovenia, Spain, Greece }\end{array}$ & 60 \\
\hline
\end{tabular}


The imbalance which happens due to changes in schedules is reflected in the frequency of the grid as shown in Fig. 2. The correlogram of the grids' frequency in Fig. 3 shows clear peaks at time lags of multiples of half an hour indicating that changes of schedules often occur with half-hourly or hourly intervals. It is obvious that the market design influences the behaviour of the system.

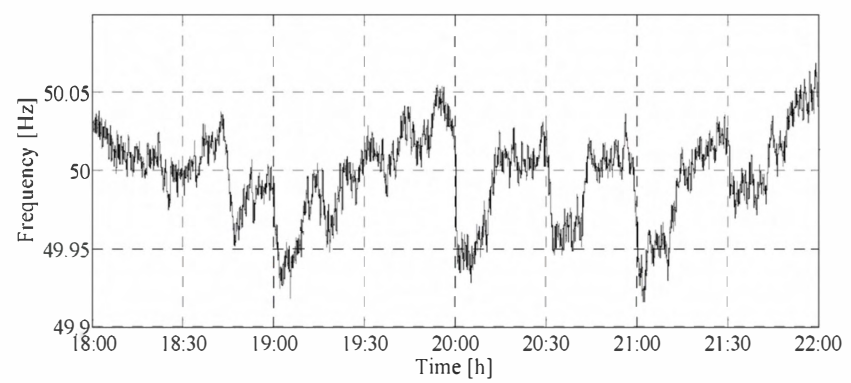

Fig. 2. Frequency deviations occur at half-hour and hour transitions. The grid frequency was measured in the Netherlands on Feb. $2^{\text {nd }} 2009$.

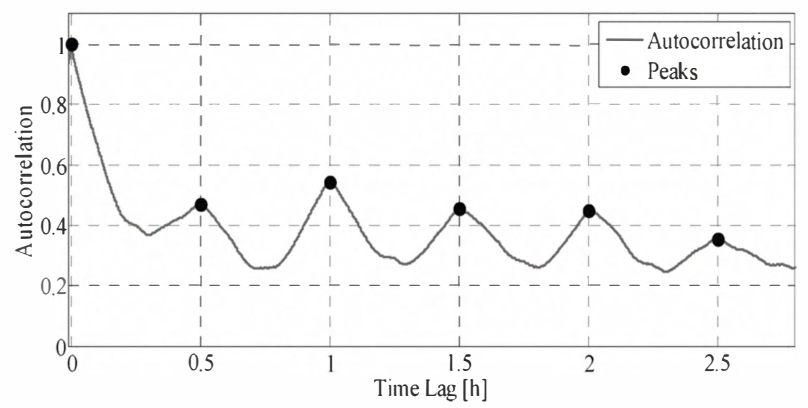

Fig. 3. Correlogram of the grids' frequency. Peaks occur at half-hourly intervals, indicating that trades happen at half-hourly and hourly intervals Clearly the market has an effect on the balance in the grid. Because of noise, 15 minute transactions cannot be traced back in the correlogram.

\section{A. Effect of PTU length on balancing systems}

In [5] and [6] the options of decreasing the period of time for electricity trade, to mitigate the effect illustrated in Fig. 2, were analysed. Changing the PTU length however has additional effects. As the TSO is responsible for settling the momentary imbalance and the imbalance for smoothing crossborder transactions, while the BRPs are concerned about the energy content of its trade in the whole PTU, the expectation is that decreasing the PTU length will lead to more imbalances for the BRP while it mitigates the effort of the TSO. With a model this was quantified.

\section{B. Methodology}

To evaluate the efforts of TSO and BRPs in a certain market area to settle the imbalance in the system, first the three types of imbalance, as explained in section 2 of this paper, had to be modelled. Two weeks (Jan $25^{\text {th }} 2010$ until Feb $6^{\text {th }} 2010$ ) of load data with a 4 seconds resolution, two years of load data with 15 minutes resolution and one year (2009) of import and export data were acquired from the TSO of the Netherlands. An assumed prediction $\mathrm{L}_{\text {pred }}(\mathrm{t})$ of the load $\mathrm{L}(\mathrm{t})$ was generated for the model using the persistence method as in (4) which often outperforms more advanced methods in short-term predictions [15]. A prediction time $\tau_{\text {pred }}$ of 15 minutes was chosen which led to a Mean Absolute Error (MAE), that can be found with (5), of $2 \%$.

$$
\begin{aligned}
& L_{\text {pred }}(t)=L\left(t-\tau_{\text {pred }}\right) \\
& M A E=\left|\frac{L_{\text {pred }}(t)-L(t)}{L(t)}\right| \cdot 100 \%
\end{aligned}
$$

It was assumed that BRPs make their generation schedules, based on the predicted load and that the generation schedules consist of stepwise blocks. The power generation schedules $\mathrm{S}(\mathrm{t})$ are calculated using (6). $\mathrm{T}_{\mathrm{ptu}}$ is defined as the length of each programme time unit PTU. The actual required schedule $R(t)$ is based on the actual load and can be derived with (7).

$$
\begin{aligned}
S(t) & =\frac{\int_{P T U_{k}} L_{\text {pred }}(t) d t}{T_{p t u}}, & & t \in P T U_{k} \\
R(t) & =\frac{\int_{P T U_{k}} L(t) d t}{T_{p t u}}, & & t \in P T U_{k}
\end{aligned}
$$

After both schedules $S(t)$ and $R(t)$ have been created, the imbalances within the PTU (ACE(t)) and over the PTU (I(t)) can be analysed with (8) and (9) respectively.

$$
\begin{aligned}
& A C E(t)=L(t)-R(t) \\
& I(t)=S(t)-R(t)
\end{aligned}
$$

The actual load, the prediction, the generation schedule and the actual production, as well as both imbalances can be are displayed in Fig. $4 \mathrm{a}$ and $4 \mathrm{~b}$ respectively.

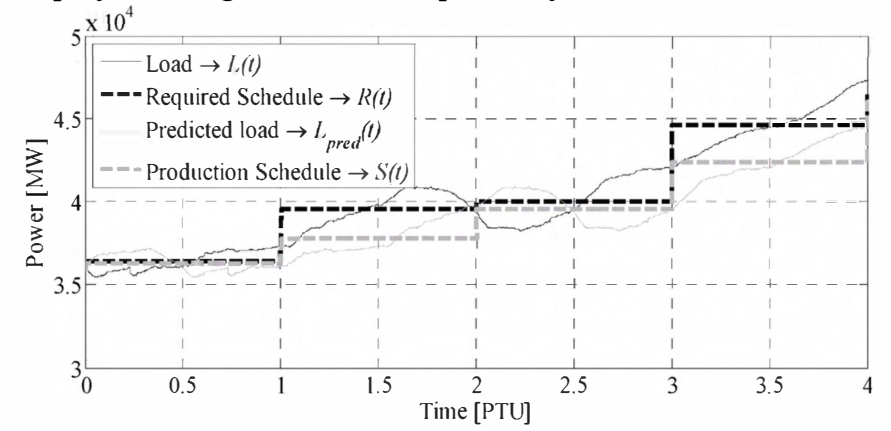

(a)

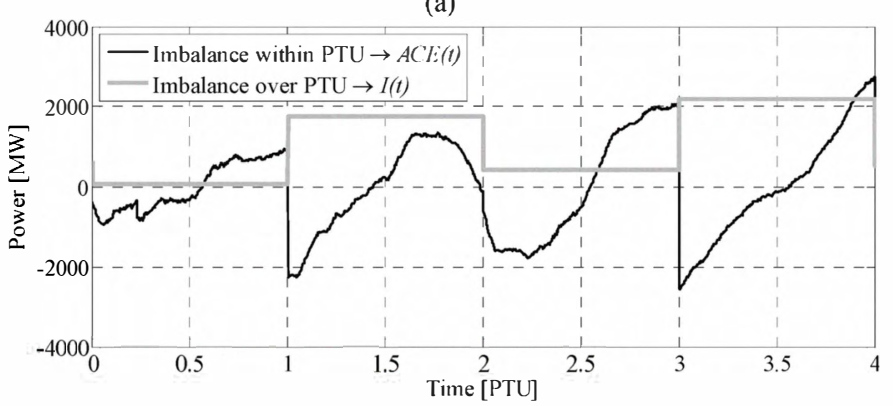

(b)

Fig. 4. Subfigure (a) displays the actual load and required schedule according to the load as well as the prediction and schedules according to the prediction. Subfigure (b) shows the imbalances within the PTU and over the PTU due to schedule differences and due to the difference between generation schedule and actual load. 
The imbalance due to cross-border transactions $\left(I_{x}\right)$ was found by assuming that the interval, at which cross-border transactions are scheduled, is equal to the PTU length. Furthermore it was assumed that the linear interpolation occurs from 5 minutes before the PTU crossing to 5 minutes after the PTU crossing. The hourly cumulative exchange data (in MWh) from 2009 was interpolated to obtain a cumulative exchange schedule with a resolution equal to the PTU length. The first derivative of this signal corresponds with the exchange schedule while the second derivative corresponds with the step size $(\Delta X)$ in between PTUs. Next, the effort for settling this type of imbalance per PTU was found using (10).

$$
I_{x}\left(P T U_{k}\right)=\frac{1}{2} \cdot\left|\Delta X\left(P T U_{k}\right)\right| \cdot 5 \mathrm{~min}
$$

The yearly effort for all three types of imbalances $\left(E_{a}=\right.$ within PTU; $E_{b}=$ over PTU; $E_{c}=$ between PTUs) was found using (11), (12) and (13) respectively.

$$
\begin{aligned}
& E_{a}=\sum_{\text {year }}|A C E(t)| \\
& E_{b}=\sum_{\text {year }}|I(t)| \\
& E_{c}=\sum_{\text {year }} I_{x}(P T U)
\end{aligned}
$$

\section{Results}

Simulations with multiple PTU lengths were performed and the results are displayed in Fig. 5. The figure indicates the effort (absolute energy) as a percentage of the yearly electricity consumption for both the TSO and the BRPs.

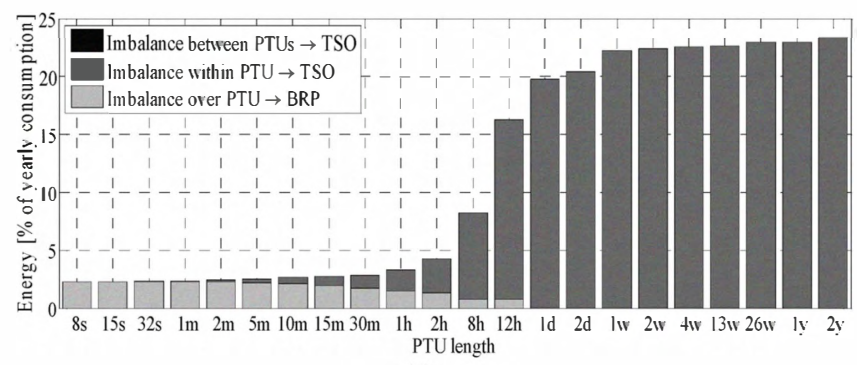

(a)

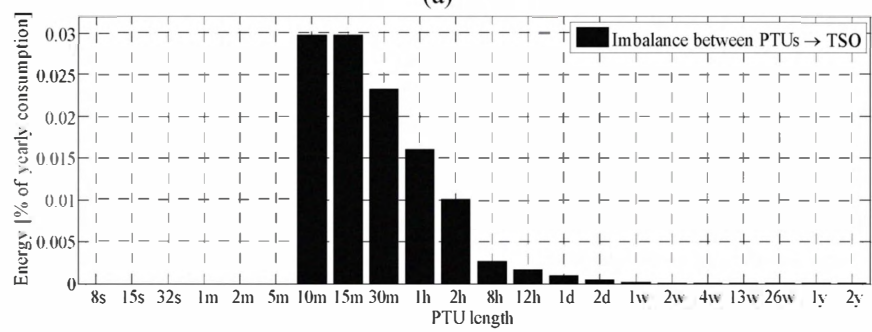

(b)

Fig. 5. Distribution of effort due to the three types of imbalance with PTU lengths varying from 8 seconds to 2 years. Subfigure (a) shows the combined effort while subfigure (b) is a zoom of the imbalance between the PTUs as this is not clearly visible in (a).

It can be concluded from the results that the balancing effort for BRPs increases as PTUs get shorter. The balancing effort for BRPs decreases as the PTUs get longer. For the TSO this is vice versa. Shorter PTUs result in less effort while longer PTUs result in more effort. Therefore, it can be concluded that changing the PTU length is a way to distribute the effort for balancing between the TSO and the BRPs. Nevertheless the total effort does not remain equal but increases as the PTU length also increases. For PTU lengths longer than one day the combined effort remains almost equal due to the repetitiveness of load curves in the subsequent day. The effort for balance due to smoothing of cross-border exchanges is marginal compared to the effort for the other two types of balancing.

The different PTU lengths which are currently in use in different countries in the European power system put extra constraints on cross-border energy trades [3], [13]. The results in this section show that when defining a common PTU length, the resulting distribution of efforts among BRPs and the TSOs in balancing should be taken into account.

\section{Gate-Closure Time}

In an electricity market, different options exist to trade electricity. First of all, electricity can be traded via bilateral contracts. Secondly, electricity can be traded via day-ahead or via intraday spot markets. For each PTU a BRP should mention its net trade to the TSO. If in real-time the actual exchange with other parties varies from the beforehand stated value, the BRP is obliged to trade energy with the TSO via the imbalance system. In general it can be stated that the closer to real-time the energy is traded, the higher the price will be, as the uncertainty of not being able to either sell or buy the energy, will increase. As mentioned in section 1, at the GateClosure Time (GCT), all parties should notify their TSO about their expected physical exchanges and options for bilateral trades cease.

As predictions for load and generation tend to be more accurate as the prediction horizon decreases, the predictions for the beginning of the day after GCT will generally be of better quality than predictions for the end of the day. Resulting from that, the imbalance will increase during the day as the time beyond the GCT increases. Often it is stated by BRPs [15] that a delay of the GCT or a rolling GCT would lead to improved system balance. As procuring energy via the imbalance system is in general more expensive than via bilateral trade or via the day-ahead spot market, the delay of the GCT would lead to improved biddings by stochastic generation in the spot market [15]. Therefore a delay of the GCT could be an effective means for countering the increased uncertainty and fluctuation on the supply side due to stochastic (renewable) generators such as wind generation.

\section{A. Methodology}

To evaluate the distribution of imbalances during the day after GCT, one year (2009) of imbalance data from the Dutch TSO was acquired. In the Netherlands the GCT is set at 14.00 hour on the day before delivery. The measurements indicate the amounts of energy per PTU (of 15 minutes) bought or sold by the TSO from the BRPs to settle the balance. First the data was split up into 4 sections for each of the four seasons in the 2009. Next for each of the 96 PTUs of all days per season, the imbalances were analyzed with a histogram. To evaluate the 
distribution of imbalance during the day, the histograms for each PTU per day were combined.

\section{B. Results}

The distributions of imbalances in the Netherlands during the day for each season in 2009 are displayed in Fig. 6 (a to d).

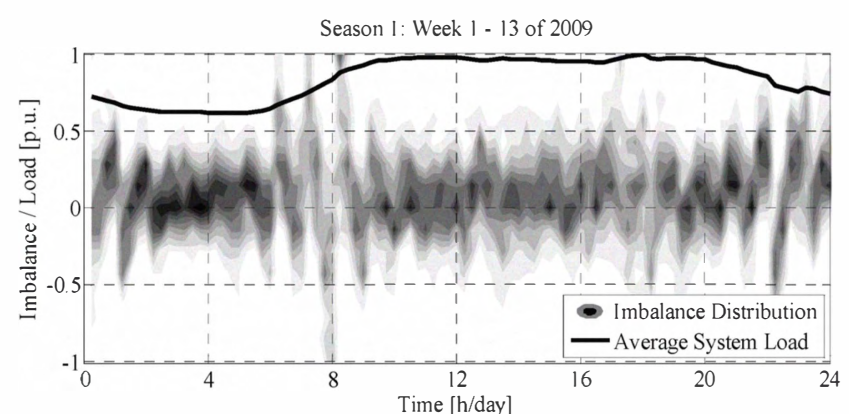

(a)

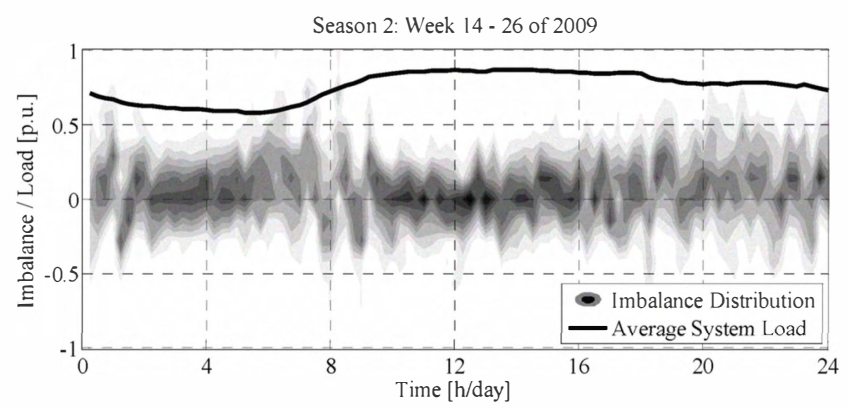

(b)

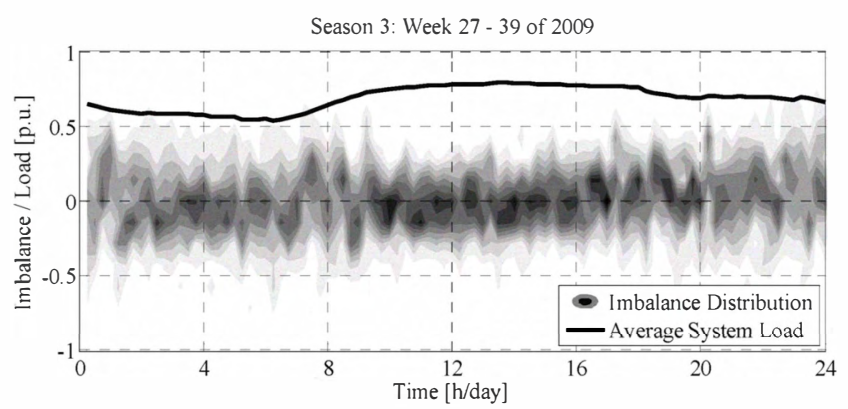

(c)

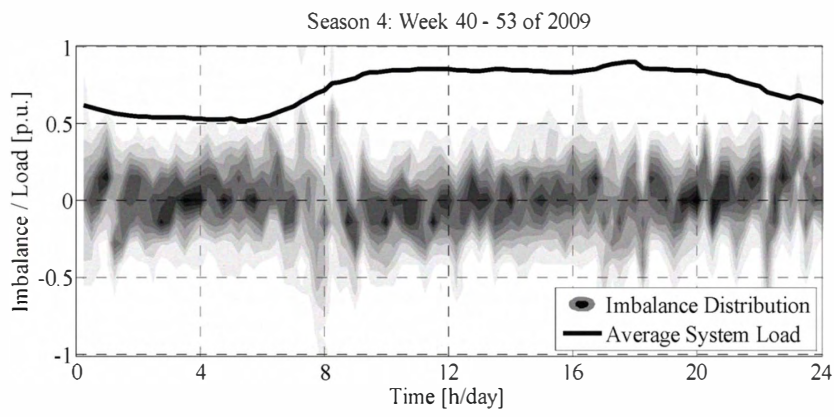

(d)

Fig. 6. Distribution of imbalances during the day in the Netherlands in four seasons (subfigures a to d) in the year 2009 and the system load in the Netherlands. Both the imbalances and the system load are normalised with base values of $500 \mathrm{MW}$ and $16000 \mathrm{MW}$ respectively.

From Fig. 6 it can be concluded that the spread of imbalance during the day does not increase. In all 4 seasons the spread of imbalance is correlated with the slope of the load curve. A high slope leads to a higher unpredictability.

As the increasing unpredictability during the day of certain generators remains while no increase in the system imbalance spread can be found, it means that the BRPs use other resources besides the imbalance system from the TSO to match their physical exchange with their expected exchange as illustrated in Fig. 7. These other options are bilateral trades, own generation/load control or, in some countries, an intraday market. In general it can be stated that the other options to settle imbalance are less efficient.

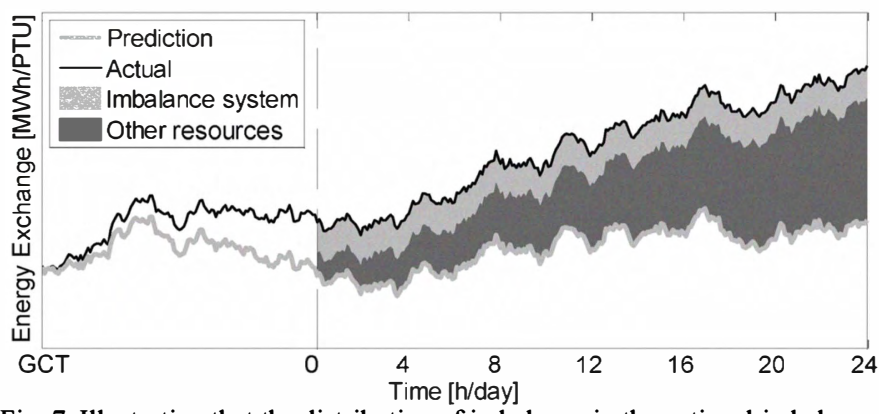

Fig. 7. Illustration that the distribution of imbalance in the national imbalance system remains the same while prediction errors increase during the day after GCT, the BRPs use increasingly other resources for their internal balancing during the day.

\section{CONCLUSION}

This paper discusses two design variables of balancing systems. Electrical energy transactions are scheduled per programme time unit (PTU) or a multiple of PTUs. The effect of this market design can be observed in the grids' frequency as certain imbalances repeatedly occur due to strategic (economically optimal) behaviour of BRPs. Three types of imbalances were identified, namely imbalance within the PTU, imbalance over the PTU and imbalance between PTUs. As the BRPs are responsible for settling the imbalance over the PTUs, the TSO in a control area is responsible for settling the imbalances within and between the PTUs. Using a model it is demonstrated that changing the PTU length influences the distribution of effort to restore the balance. For short PTU lengths the BRPs have to put more effort while for long PTUs the TSO has to put more effort into balancing. Remarkable is that the total effort to settle imbalance also largely depends on the chosen PTU length.

A second design variable is the gate-closure time. GCT is the time at which all trading schedules for the complete next day need to be send to the TSO for a consistency check. Usually the GCT also is the last time at which trades with other parties can be made. After GCT the BRPs therefore have only limited resources to avoid imbalance. Predictions for load and stochastic generation tend to be more accurate as the forecasting time is shorter. Therefore the expectation was that delaying the GCT could be seen as an option to reduce system imbalance and therefore also lower the required amount of reserves. However, by investigating the distribution of imbalance during the day it was concluded that the system imbalance is not related to the time after GCT. The result indicates that BRPs use other means to settle their internal balance and take advantage of their own resources and the adjustment market. 


\section{ACKNOWLEDGEMENTS}

This article is part of the project RegelDuurzaam, which is an EOS-project (Energy Research Subsidy Project) funded by the Dutch Ministry of Economic Affairs.

\section{REFERENCES}

[1] P. Kundur, Power System Stability and Control, McGraw-Hill Inc., 1994, pp. 581-626.

[2] Y. Rebours, and D. Kirschen, and M. Trotignon, and S. Rossignol, "A survey of frequency and voltage control ancillary services - part II: economic features," IEEE Transactions on power systems, vol. 22, 2007, pp. 358-366.

[3] ETSO, "Balance management harmonisation and integration, $4^{\text {th }}$ report," European Transmission System Operators, Tech. Rep., 2007.

[4] M. Gibescu, and A. J. Brand, and W. L. Kling, "Estimation of variability and predictability of large-scale wind energy in The Netherlands," Wind Energy, vol. 12, 2009, pp. 241-260.

[5] T. Weissbach, and E. Welfonder, "High frequency deviations within the European Power System: Origins and proposals for improvement," 2009 IEEE/PES Power Systems Conference and Exposition, 2009, pp. 1-6.

[6] UCTE, "UCTE ad-hoc group "frequency quality investigation, excerpt of the final report," Union for the Co-ordination of Transmission of Electricity, Tech. Rep., 2008, pp. 1-4. [Online]. Available: http://www.entsoe.eu/fileadmin/user_upload/_library/publications/ce/oth erreports/090330_UCTE_FrequencyInvestigationReport_Abstract.pdf.

[7] ENTSO-E. "Operation Handbook, Policy 1: Load-Frequency Control and Performance" European Network of Transmission System Operators, Tech. Rep., 2009. [Online]. Available: http://www.entsoe.eu/_library/publications/ce/oh/Policy1_final.pdf.

[8] R. Beune, and F. A. Nobel, "System balancing in the Netherlands," Proceedings of Methods to Secure Peak Load Capacity on Deregulated Electricity Markets, Market Design, 2001.

[9] TenneT TSO b.v. "De onbalansprijssystematiek per 01-01-2001, herzien per 26-10-2005" Tech. Rep., Arnhem, The Netherlands, 2005 [In Dutch], [Online]. Available: http://www.tennet.org/images/De\%20onba lansprijssystematiek\%20per\%2001012001\%20herzien\%20per\%202610 2005\%20_2_tcm41-11583.pdf.

[10] Ministerie van Economische Zaken, "Elektriciteitswet 1998, Wet van 2 juli 1998, houdende regels met betrekking tot de productie, het transport en de levering van elektriciteit," 2005. [Online]. Available: http://www.dte.nl/images/Elektriciteitswet-1998 tcm7-100195.pdf.

[11] Directie Uitvoering en Toezicht Energie. "Systeemcode" Tech. Rep., The Hague, The Netherlands, 2007 [In Dutch], [Online]. Available: $\mathrm{http}: / / \mathrm{www}$. energiekamer.nl/images/Systeemcode_28_februari_2009_tc m7-127999.pdf.

[12] S. Stoft, Power System Economics - Designing Markets for Electricity, Wiley-IEEE Press, 2002.

[13] ETSO, "Current state of balance management in Europe," European Transmission System Operators, Tech. Rep., 2003.

[14] J. Frunt, and A. Kechroud, and W. L. Kling, and J. M. A. Myrzik, "Participation of distributed generation in balance Management," 2009 IEEE Bucharest PowerTech, IEEE, 2009, pp. 1-6.

[15] L. Landberg, and G. Giebel, and H. A. Nielsen, and T. Nielsen, and H. Madsen, "Short-term Prediction? An Overview," Wind Energy, vol. 6, 2003, pp. 273-280.

[16] W. L. Kling, and J. Frunt, "User Acceptance of Ancillary Service Markets," to be published in Cigré 2010, Paris, France, 2010.

\section{BIOGRAPHIES}

Jasper Frunt was born in 's-Hertogenbosch in 1981 $\mathrm{He}$ received his $\mathrm{B}$. degree in electrical engineering in 2003 from the University of Professional Education in 's-Hertogenbosch. In 2006 he received his M.Sc. degree in sustainable energy technology from Eindhoven University of Technology. For his graduation projects he worked with Kema N.V. and TenneT TSO bv (Dutch Transmission System Operator) respectively. Currently he is a $\mathrm{PhD}$ in the EOS (Energy Research Subsidy) project 'RegelDuurzaam' for Eindhoven University of Technology. His research focuses on current and future deployment, legislation and organisation of control power for balance management.

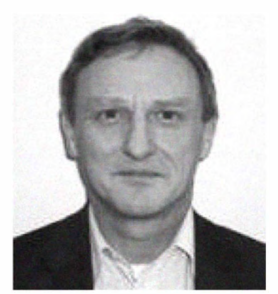

Wil L. Kling received his MSc. degree in electrical engineering from the Technical University of Eindhoven in 1978. Since 1993 he has been a (parttime) professor in the Department of Electrical Engineering at Delft University of Technology, in the field of Power Systems Engineering. Since 2008, he is a full-time professor at Eindhoven University of Technology where he is leading research programs on distributed generation, integration of wind power network concepts and reliability. Prof. Kling is involved in scientific organisations such as CIGRE and the IEEE. As Netherlands' representative, he is a member of CIGRE Study Committee C6 Distribution Systems and Dispersed Generation, and the Administrative Council of CIGRE.

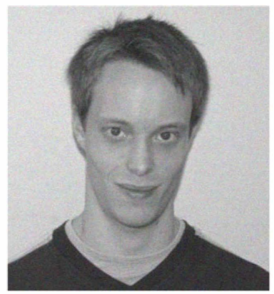

Ralph M. Hermans is a $\mathrm{PhD}$ student at Eindhoven University of Technology, Department of Electrical Engineering, within the Control Systems group. He received his Bachelors and Masters degree in Electrical Engineering in 2006 and 2008, respectively, both cum laude. His master research concerned low-complexity model predictive control of electromagnetic actuators for automotive applications. Currently, Ralph is working on the EOS RegelDuurzaam project, involving distributed and decentralized control of future electrical power systems. His main research interests are: Genera system theory, model predictive control, optimal control and distributed control.

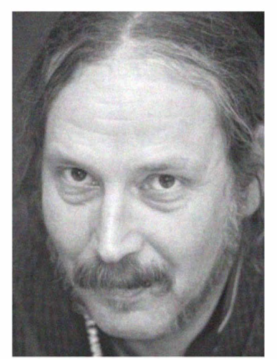

Frank A. Nobel received his M.Sc. degree in Structural Geology from the University of Amsterdam in 1981. He joined the Dutch Electricity Generating Board N.V. Sep in 1988 at the Planning and Research Department, dealing with long term and medium term load forecasting. Presently employed by TenneT TSO bv, the Dutch Transmission System Operator, he is involved in market design and system operations issues, mainly in relation to system balancing.

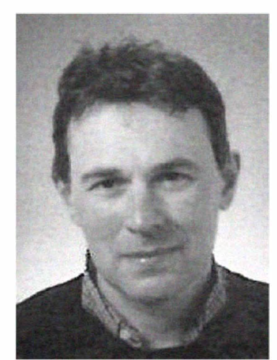

Wouter W. de Boer received his M.Sc. degree in mechanical engineering specialized in control engineering from the Technical University of Delft in 1987. Thereafter he joined KEMA in Arnhem. Within KEMA he dealt with modeling and control design of energy-related conversion systems. For example, modeling and control design have been carried out for wind turbines, primary and secondary control of power systems. A simulation model was developed to analyze the adjustment of primary and secondary control. With this model also balancing issues were analyzed in the case of large amount of wind energy. A recent activities matters a feasibility study of a new concept for large scale energy storage: an inverse pump accumulation system placed on an artificial island on the North Sea (so called Energy Island). 